\title{
Monitoring the Domiciliary and Peridomiciliary Invasion Process of Triatoma rubrovaria in the State of Rio Grande do Sul, Brazil
}

\section{Carlos Eduardo Almeida $/ * /+$, Marcio Costa Vinhaes**, Josimar Ribeiro de

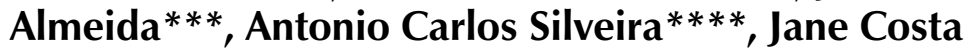

\begin{abstract}
Núcleo de Informatização, Coleção Entomológica, Departamento de Entomologia, Instituto Oswaldo Cruz, Av. Brasil 4365, 21045-900 Rio de Janeiro, RJ, Brasil *Centro Universitário de Barra Mansa, Barra Mansa, RJ, Brasil **Fundação Nacional de Saúde, Brasília, DF, Brasil ***Coppe, Universidade Federal do Rio de Janeiro, Rio de Janeiro, RJ, Brasil ****Organização Pan-americana de Saúde, Brasília, DF, Brasil
\end{abstract}

The presence of Triatoma rubrovaria in Brazil has only been confirmed in the States of Parana and Rio Grande do Sul (RS), where it is found naturally infected with Trypanosoma cruzi. In the wild environment it occurs in rocky habitats and has an eclectic diet, feeding from cockroaches, reptiles and mammals. Data from the Chagas Disease Control Program obtained by the Fundação Nacional de Saúde, between 1975 and 1997, indicate a growing domiciliary and peridomiciliary invasion of $\mathrm{T}$. rubrovaria in $R S$, where it has become the most frequently Triatominae species captured in this state since the control of Triatoma infestans. In order to monitor this process, we analyzed collection data derived from 22 years of control campaigns against $\mathrm{T}$. infestans. Collection data for triatomines from domestic habitats show an inverse relationship, with high numbers of $\mathrm{T}$. infestans and low numbers of T. rubrovaria during 1976-1987, compared to the following ten years, 1986-1997, when the number of $\mathrm{T}$. infestans dropped drastically and that of $\mathrm{T}$. rubrovaria increased. There are no consistent indications of intradomiciliary colonization by $\mathrm{T}$. rubrovaria, since only low numbers of nymphs have been captured in the intradomiciliary ecotopes. Nevertheless, this species appears to have preadaptive characteristics for anthropic ecotopes, and should be kept under constant epidemiological surveillance.

Key words: Triatoma rubrovaria - domiciliation - invasion process - Brazil

Triatoma rubrovaria (Blanchard, 1843) (Hemiptera, Reduviidae, Triatominae) is widespread in Uruguay and some neighbouring parts of northeastern Argentina, where it is mainly found among exfoliate rocks often known as 'pedregales'. It is considered a generalist species, feeding from a wide variety of vertebrate and invertebrate hosts (Salvatella et al. 1994, 1995). In Brazil, it has been confirmed only in the southern States of Paraná and Rio Grande do Sul (RS). Lent (1942) mentions T. rubrovaria (cited as Eutriatoma rubrovaria) as an exclusively silvatic species found in rockpiles and peridomestic habitats in RS, but only rarely en-

\footnotetext{
Supported by Fundação Nacional de Saúde, agreement term \# 1159/98.

Presented in the International Symposium on the Advances in Knowledge of Chagas Disease 90 Years after its Discovery in Rio de Janeiro, Brazil (1999).

${ }^{+}$Corresponding author. Fax: +55-21-590.3545. E-mail: calmeida@nit.mtecnet.com.br

Received 30 November 1999

Accepted 14 July 2000
}

countered in human dwellings. Subsequent authors have also mentioned the finding of this species in domestic habitats, but with no indication of successful domestic colonization (Di Primo 1957, Lucena 1959, Correa 1968, Lent \& Wygodzinsky 1979). However, its potential for colonizing human habitations was recognized by Silveira and Rezende (1994), and survey data over the last 20 years shows that its presence in human dwellings has increased in southern Brazil. Salvatella et al. (1994) demonstrated that is does feed on humans and Silva and Silva (1993) demonstrated that it is a highly competent vector of Trypanosoma cruzi, causative agent of Chagas disease.

In this study we present an analysis of collection records of $T$. rubrovaria from RS based on data provided by Chagas Disease Control Programme (PCDCH) of the Fundação Nacional de Saúde (FNS) of RS. The analysis illustrates the increasing presence of $T$. rubrovaria in houses in rural areas of RS, and suggests that this species is progressively invading houses in areas where the main domestic vector of Chagas disease, $T$. infestans, has been eliminated through vector control interventions. 


\section{MATERIALS AND METHODS}

Study area - RS is the southernmost state of Brazil, bordering on Uruguay. Its capital city is Porto Alegre $\left(30^{\circ} 01 \mathrm{~S}, 51^{\circ} 13 \mathrm{~W}\right)$. The state covers an area of 282,062 km2, and is divided into 467 municipalities (IBGE 1997). There are seasonal deciduous woodlands in the extreme north of state, but the area considered in this study (between $27^{\circ}$ $31^{\circ} \mathrm{S}$, and $53^{\circ}-56^{\circ} \mathrm{W}$ ) is predominantly of savannalike or steppe-like subtropical mixed prairies (IBGE 1997). For this study, we considered overall data from the endemic area of state (Fig. 1) together with more detailed data from two representative municipalities of Quaraí $\left(30^{\circ} 23 \mathrm{~S}, 56^{\circ} 27 \mathrm{~W}\right)$ and Santana do Livramento $\left(30^{\circ} 53 \mathrm{~S}, 55^{\circ} 31 \mathrm{~W}\right)$.

Data set - Data from PCDCH of FNS of RS obtained during 1975-1999 provided information on the number of house searches carried out, and the number of houses and peridomestic habitats where $T$. rubrovaria and $T$. infestans were collected. We selected a subset of this data in order to analyse: (1) the total number of house searches and the number positive for T. rubrovaria in $12 \mathrm{mu}$ nicipalities during 1975-1989; (2) the relationship between the total number of $T$. rubrovaria collected in intradomiciliary and peridomiciliary habitats for the whole state during 1976-1989; (3) the time series of collections of T. rubrovaria and T. infestans in the state of during 1975-1997; (4) the capture index of $T$. rubrovaria and $T$. infestans during the period 1975-1999 [capture index $=$ (number of bugs collected/number of houses surveyed) '100]; (5) the ratio of percent positive domiciliary units (positive domiciliary unit $=$ house plus associated peridomestic areas) where at least one triatomine was found, for $T$. infestans and T. rubrovaria in the municipalities of Quaraí and Santana do Livramento during 1977-1990; and (6) total number of localities where T. rubrovaria was collected in 1995.

According to standard FNS procedures, bugs were collected during manual searches using torch and forceps, aided by chemical dislodgants where necessary. The FNS field technicians usually carry

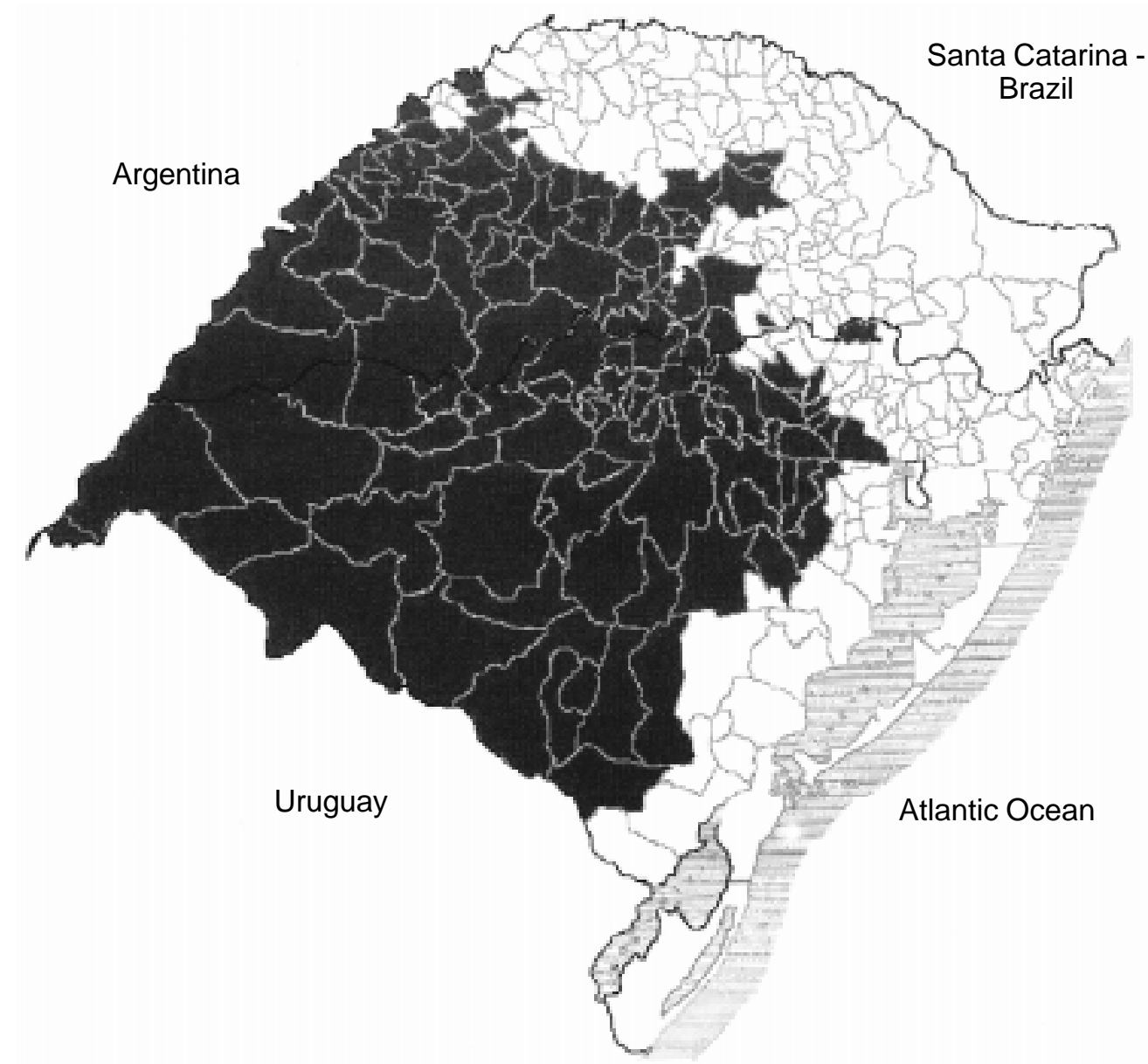

Fig. 1: distribution of Triatoma infestans in the State of Rio Grande do Sul, in the 1975-1983 period (Silveira et al. 1984) 
out such searches of each house and its associated peridomestic areas within a radius of about $100 \mathrm{~m}$, registering all insects encountered outside the house as peridomiciliary.

\section{RESULTS}

Data for 1975-1989 period show that the number of houses searched by FNS personnel in 12 municipalities in RS was roughly constant around 100,000 houses per year (Fig. 2). Over this same period however, the number of houses found positive for T. rubrovaria increased from zero in 1975, to around 10 per year up to 1979 , and then to over 100 houses per year (Fig. 2). The 1976-1978 period represents the beginning of regular encounters of T. rubrovaria in houses. The 1979-1981 period shows a transition from around 10 houses found infested each year, up to over 100 in 1981/
1982, after which the number of houses positive for $T$. rubrovaria remains roughly constant at around 200 houses per year. During the 1976-1979 period, most of the reports of house positivity reflected peridomestic rather than intradomestic colonisation (Fig. 3). From 1980 to 1984, however, T. rubrovaria was more frequently encountered in intradomiciliary habitats $(i d+)$ than in peridomestic $(p d+)$. In 1981, both values were lower than 100 houses, but the following years show the transition of the invasive installation phase, with he $i d+$ and $p d+$ rates reaching 200 houses in the subsequent years. The $i d+$ remains higher than $p d+$ in the 1980-1982 period, while from 1983 onwards there is trend to greater positivity in the peridomicile $(p d+>i d+)$ until 1988, but in 1989 there was another steep rise in the indomiciliary infestation rate.

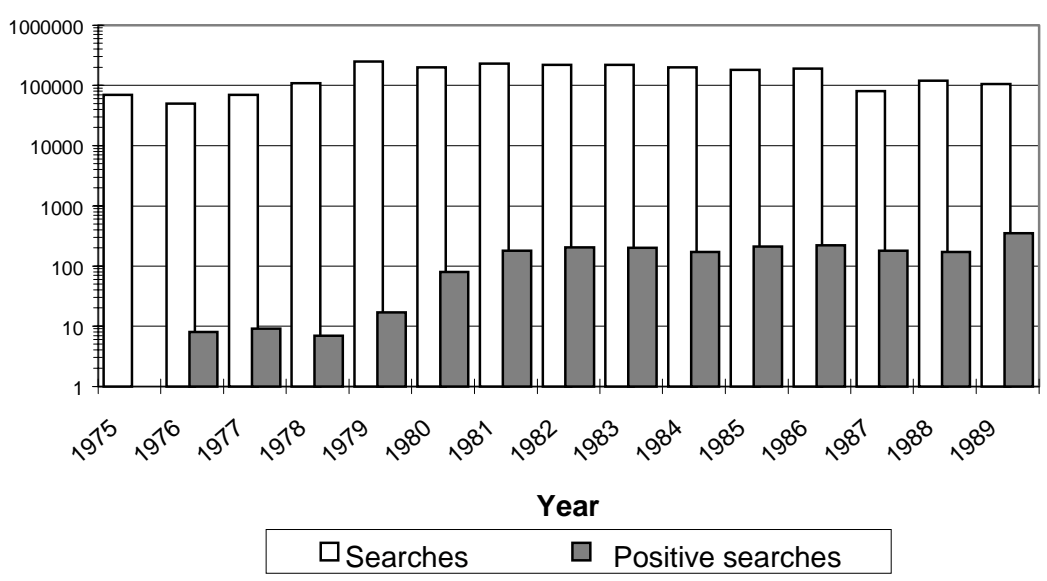

Fig. 2: total number of searches performed compared to the number positive for Triatoma rubrovaria, in 12 municipalities of the State of Rio Grande do Sul, in the 1975-1989 period.

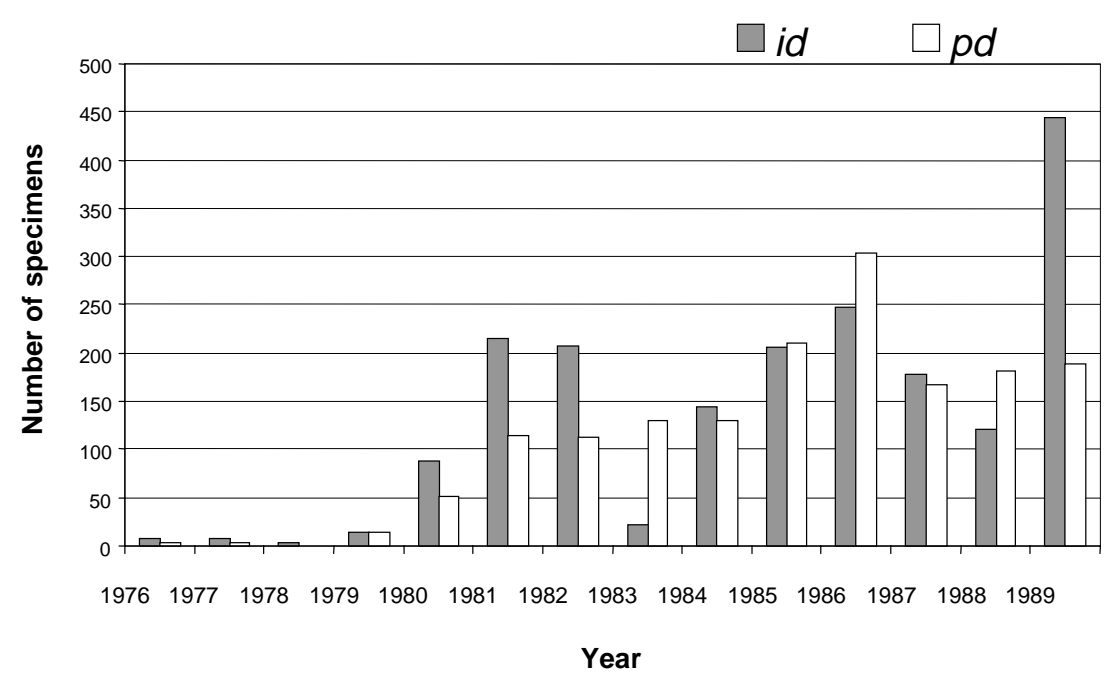

Fig. 3: total number of Triatoma rubrovaria specimens collected in the peridomicile $(p d)$ and in the intradomicile $(i d)$, in the State of Rio Grande do Sul, in the 1975-1989 period. 
Comparison of the total numbers of $T$. infestans and T. rubrovaria captured in RS during the 19751997 period shows that in 1975 only two $T$. rubrovaria were captured compared to 5,823 $T$. infestans (Fig. 4). From 1975 onwards, the number of $T$. rubrovaria increased steadily up to 1983 , when 524 specimens were captured. In the following year $T$. infestans presented its highest capture rate (34,316 specimens), then declined up to 1987 and rose again during 1988-1989. In the 1993-1997 period, $T$. infestans capture rate showed a steady decrease, from 3,843 specimens captured in 1993, to 409 in 1997. During this same period, the number of $T$. rubrovaria captured rose from 770 in 1993, to 1,775 in 1997. The capture index for the two species (number collected/number houses surveyed) recapitulates this transition (Fig. 5).

The pattern of domestic invasion is shown in more detail in the two representative municipalities. The municipality of Quaraí (Fig. 6) showed low infestation rates for T. rubrovaria until 1980 $(0.3 \%)$, compared to high rates of infestation with $T$. infestans ( $\cong 0.5$ to $2.7 \%$ ). From 1980 to $1983, T$. rubrovaria was found more frequently in houses, but from 1985 onwards, while $T$. infestans was only rarely encountered, $T$. rubrovaria was found in up to $3.19 \%$ of the houses, showing levels of house infestation similar to those shown by $T$. infestans at the beginning of the control program.

In the municipality of Santana do Livramento (Fig. 7) the house infestation rate for $T$. infestans was higher than that of Quaraí, with rates reaching 4\% in 1980 when T. rubrovaria was still rare in houses. By 1983 however, the house infestation rate for T. rubrovaria began to reach that of $T$.

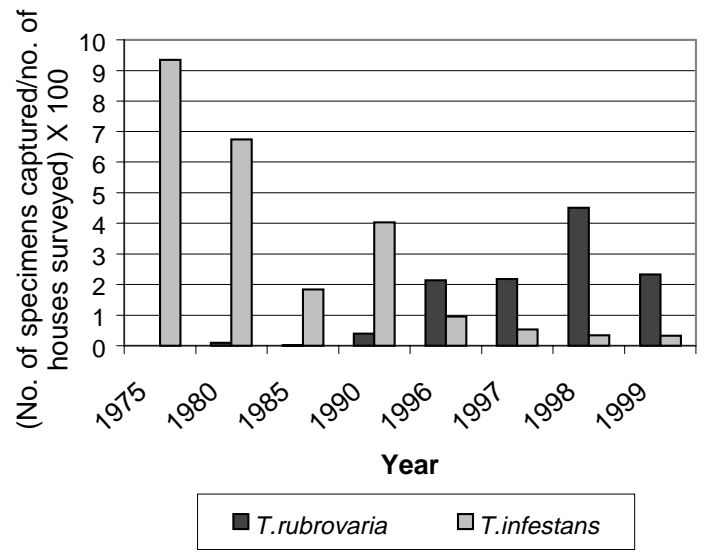

Fig. 5: capture index of Triatoma rubrovaria and T. infestans analyzed in the State of Rio Grande do Sul, in the 1975-1999 period.

infestans, and continued to rise from 1986 onwards as $T$. infestans was gradually eliminated from the houses.

Throughout RS, the recorded distribution of $T$. infestans and T. rubrovaria has changed dramatically since the data compiled by Silveira et al. (1984) for the period 1975-1983 when T. infestans was widespread (Fig. 1) but T. rubrovaria only rarely encountered. Figs 8 and 9 show the present distribution of $T$. infestans and T. rubrovaria, respectively. However, house searches carried out in 29 localities of RS in 1995, revealed nymphal stages of $T$. rubrovaria in intradomiciliary ecotopes only in four localities. Elsewhere, only adult specimens were recorded (Table).

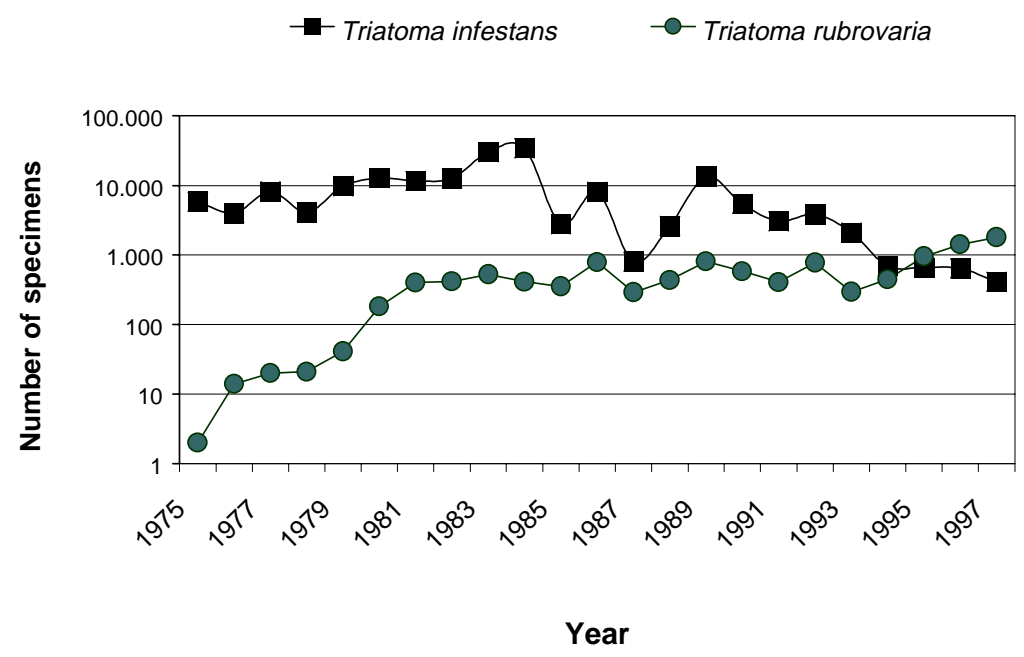

Fig. 4: total number of Triatoma infestans and T. rubrovaria specimens collected in the State of Rio Grande do Sul, in the 19751997 period. 


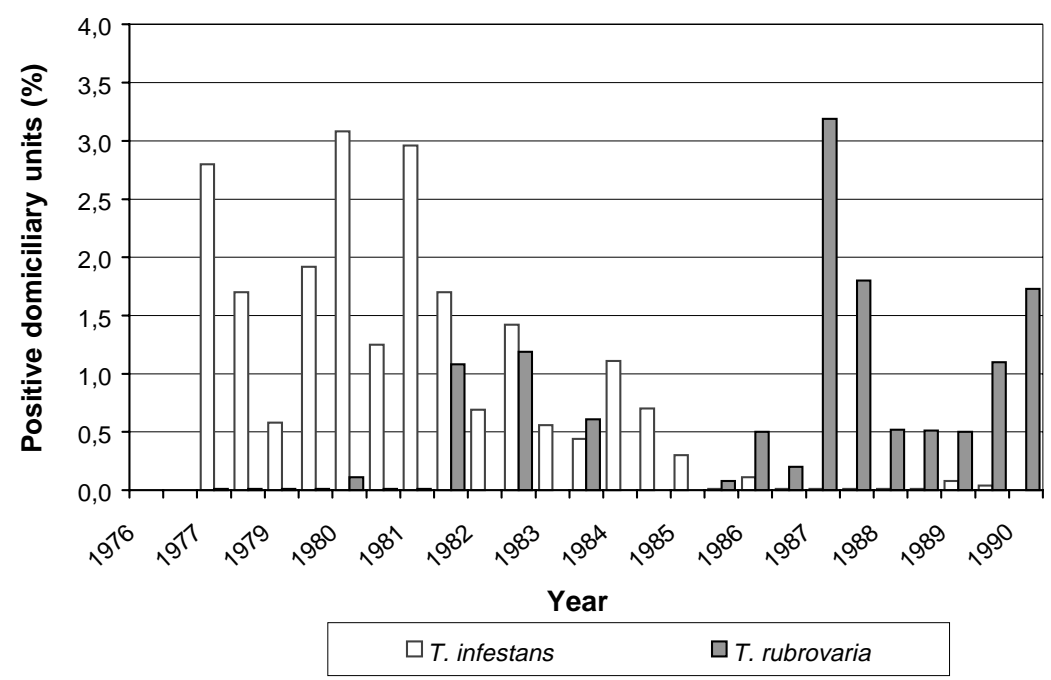

Fig. 6: percentage of domiciliary units positive for Triatoma infestans and T. rubrovaria, in the municipality of Quaraí, in the 1977-1990 period

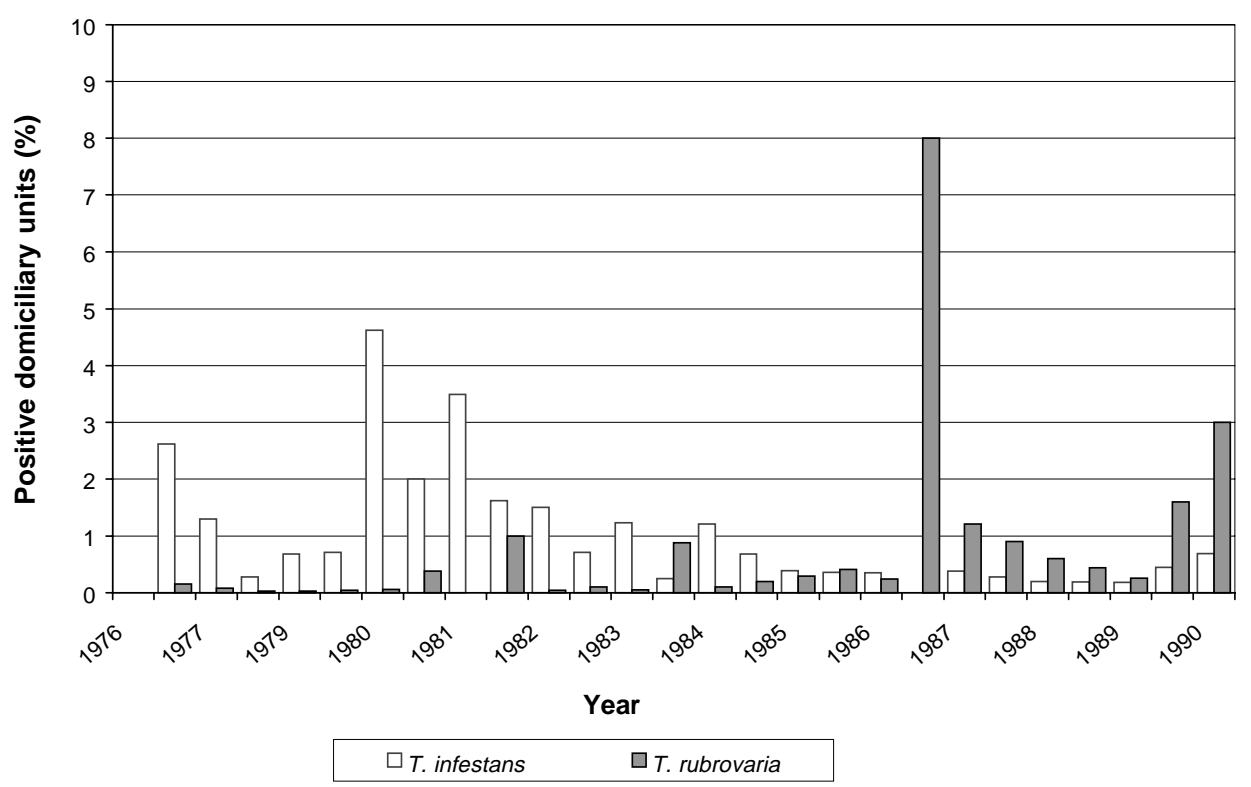

Fig. 7: percentage of domiciliary units positive for Triatoma infestans and T. rubrovaria, in the municipality of Santana do Livramento, in the 1977-1990 period

TABLE

Number of municipalities where Triatoma rubrovaria were collected in 1995, in the State of Rio Grande do Sul and its respective life stages and ecotopes

\begin{tabular}{lc}
\hline Stage/ecotope & $\begin{array}{c}\text { No. of localities which } \\
\text { presented positiveness in 1995 }\end{array}$ \\
\hline Adults/peridomicile & 2 \\
Adults/intradomicile & 20 \\
Nimphs/peridomicile & 3 \\
Nimphs/intradomicile & 4 \\
\hline
\end{tabular}

\section{DISCUSSION}

In 1975, FNS started regular operations to control Chagas disease vectors in RS, where official reports had shown a preponderance of $T$. infestans in the collections, with high levels of domiciliation and natural infection for T. cruzi. Thus, $T$. infestans was incriminated as the main vector of Chagas disease (Silveira \& Vinhaes 1999). The beginning of the control interventions in RS is represented in Figs 6 and 7 referring to the municipalities of Quaraí and Santana do Livramento, 
which show an outstanding inverse relation in the years 1976-1980, when the numbers for T. infestans were high and for T. rubrovaria were low. In 1983, the Brazilian national campaign against Chagas disease was launched leading to extensive control interventions directed mainly against $T$. infestans (Dias 1968). The resulting intensification of control activities in RS is illustrated in Fig. 4, showing a marked decline in the numbers of domestic $T$. infestans encountered from 1983 up to 1986-1987 when the national campaign was interrupted by the demands of the 1986 dengue outbreaks. Control activities resumed in 1990-1991 in line with the 'Southern Cone Initiative' against Chagas disease (Schofield \& Dias 1998), with a steady decline in the frequency of domestic $T$. infestans throughout Brazil up to the present (Silveira \& Vinhaes 1999).

Data from RS show a clear substitution of peaks between $T$. infestans and $T$. rubrovaria, although the peak house infestation rates for $T$. rubrovaria are generally lower than those previously observed for T. infestans (Figs 6, 7). Such a transition between domestic species has also been demonstrated for other regions where a decline in house infesta- tion of $T$. infestans has been followed by increasing reports of other species such as T. sordida and Panstrongylus megistus (Dias 1968, Silva et al. 1969, Diotaiuti et al. 1995).

Despite the fact that $T$. rubrovaria is autochthonous to RS, it had not been frequently found in a domiciliary habitats prior to the steady decline in $T$. infestans infestation rates. Fig. 3 shows that in the period following the national program of eradication of $T$. infestans (1983-1988), $T$. rubrovaria tended to be found with greater frequency in peridomestic habitats, but became more common in domestic habitats as the control programmes proceeded. This may suggest that $T$. rubrovaria has always invaded anthropic ecotopes on an adventitious basis, but has only begun to establish domestic populations as $T$. infestans populations have been reduced as a result of the control interventions.

According to the FNS reports, T. rubrovaria nymphs were occasionally encountered in intradomiciliary habitats, although adult stages were much more fequent especially in the warmer months (Table). Active domestic invasion by fly-

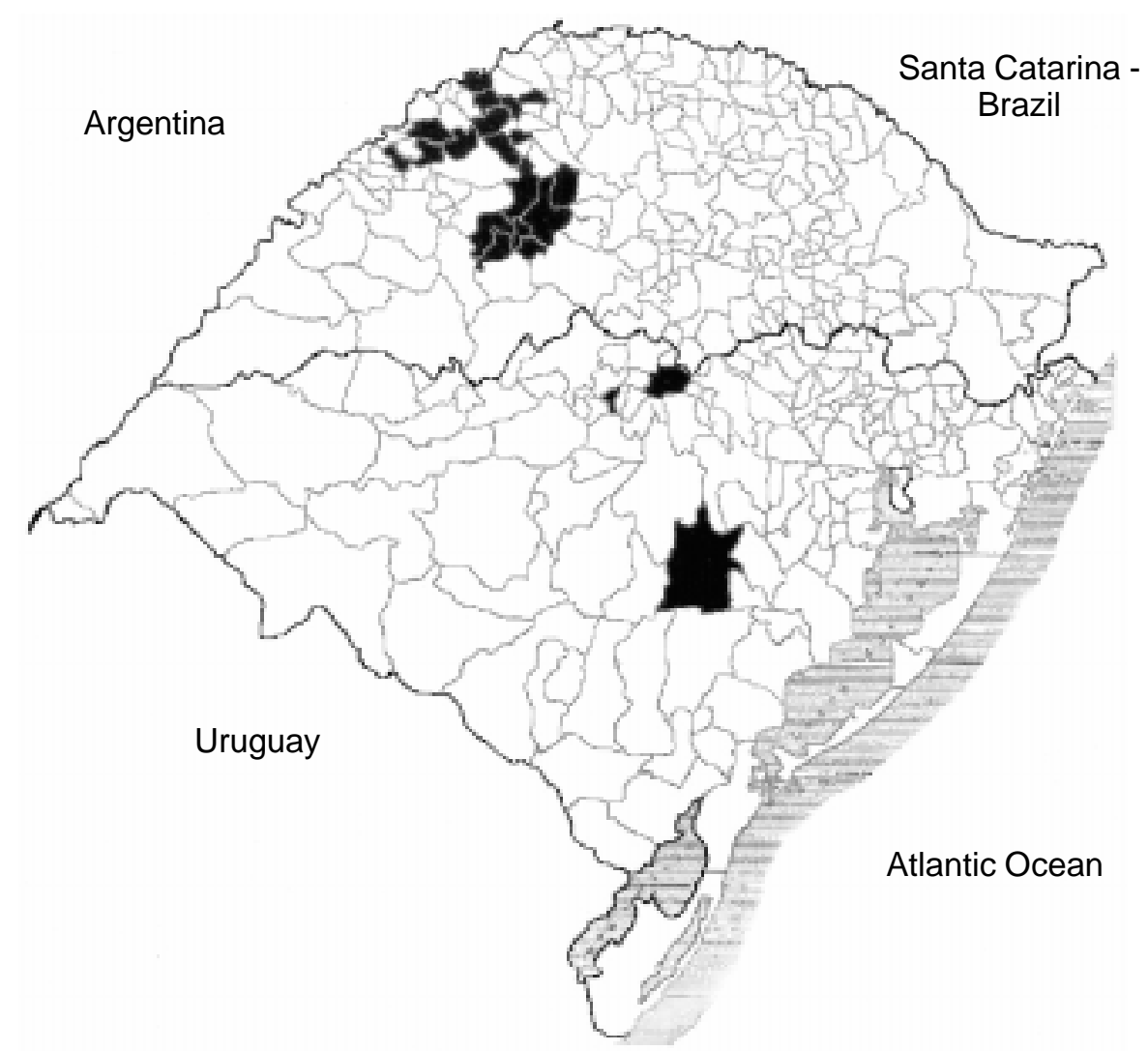

Fig. 8: current distribution of Triatoma infestans in the State of Rio Grande do Sul (Chagas Disease Control Program/Fundação Nacional de Saúde) 
ing adults of $P$. megistus is also common elsewhere in southern Brazil in the warmer months, but does not characterize domiciliation, which can only be considered after the finding of other developmental stages of the insects (eggs and nymphs) inside the houses (Forattini et al. 1970). Salvatella et al. (1995) emphasize that in Uruguay, adults of $T$. rubrovaria were only collected in the warmer months from October to March, so that the occurrence of nymphs and eggs in houses would be enough to suspect incipient domiciliation in this species.

The factors that determine the domiciliation of different species of Triatominae have not yet been completely elucidated. According to Aragão (1983), one of the main prerequisites would be feed ecletism, already confirmed for $T$. rubrovaria in Uruguay by Salvatella et al. (1994) who showed its association with several different groups of vertebrates and invertebrates in sylvatic habitats. Aragão (1983) also suggests that domestication would depend on the existence or availability of a niche to which the species would already be adapted. As mentioned by Salvatella et al. (1995), sylvatic populations of $T$. rubrovaria live amongst rockpiles, so that peridomestic habitats such as stone walls and intradomestic habitats, such as cracks in stone walled houses, would seem quite similar to its original sylvatic ecotopes. It may be that $T$. rubrovaria is a species which presents preadaptive characteristics to the domiciliary ecotope, since from the first surveys, before the control measures (1976-1984; Fig. 3) the number of specimens captured in intradomiciliary habitats was generally higher than in peridomestic habitats. These were invariably adult bugs, suggesting that T. rubrovaria flies quite frequently to encounter new habitats, and is now capable of colonising peridomestic and intradomestic habitats previously infested with $T$. infestans.

\section{ACKNOWLEDGMENTS}

To Dr Chris Schofield for critical revision of the manuscript. To the Centro Universitário de Barra Mansa for support. To the technicians of Fundação Nacional de Saúde for the field work that provided the data presented here.

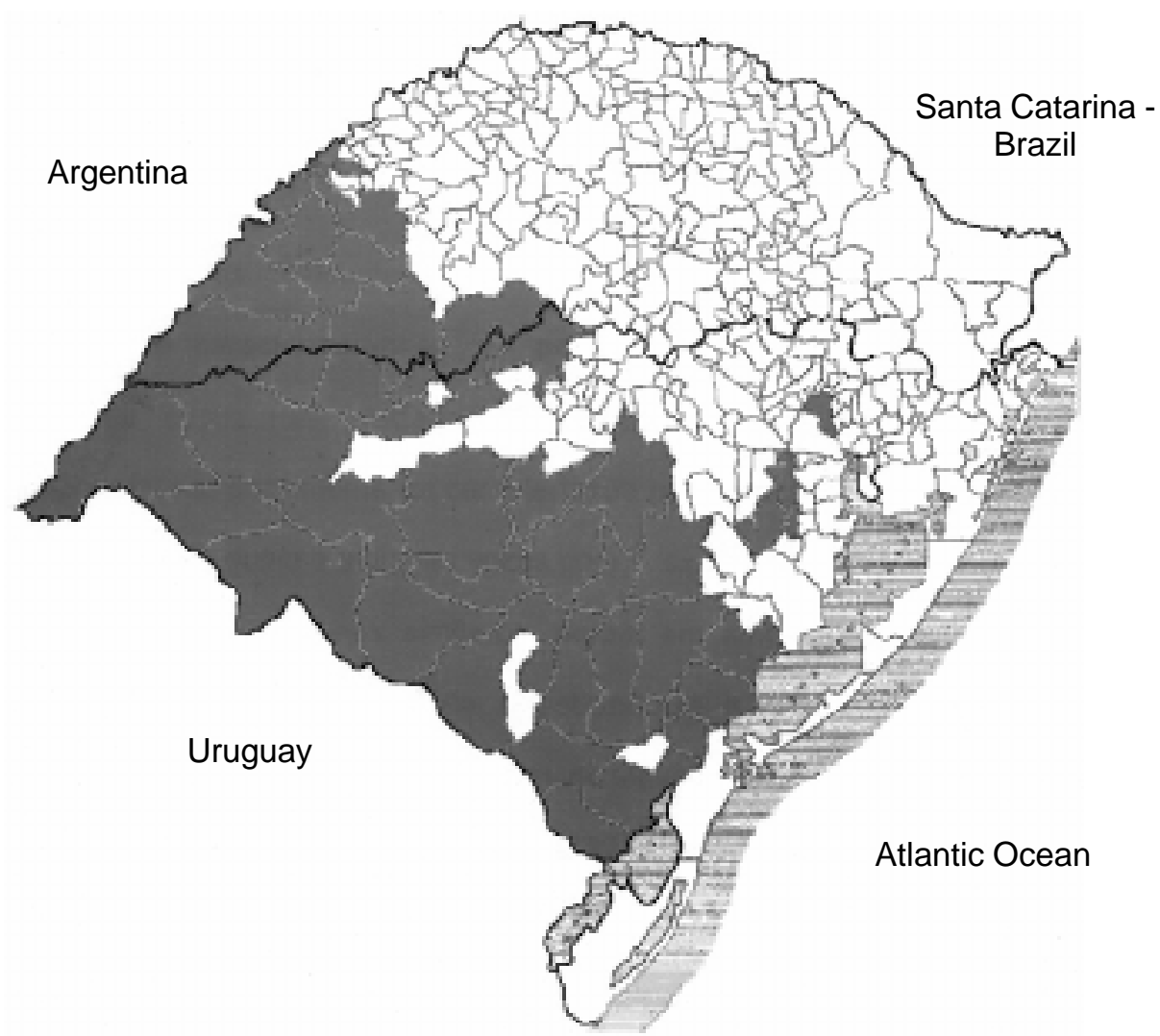

Fig. 9: current distribution of Triatoma rubrovaria in the State of Rio Grande do Sul (Chagas Disease Control Program/Fundação Nacional de Saúde) 


\section{REFERENCES}

Aragão MB 1983. Domiciliação de triatomíneos ou préadaptação à antropofilia e à ornitofilia? Rev Saúde Púb 17: 51-55.

Correa RR 1968. Informe sobre a doença de Chagas no Brasil e em especial no estado de São Paulo. Rev bras Malariol Doenç Tropical 20: 39-81.

Dias JCP 1968. Reinfestação do município de Bambuí por triatomíneos transmissores da doença de Chagas (2a nota). Mem Inst Oswaldo Cruz 66: 197-208.

Dias JCP 1987. Control of Chagas disease in Brazil. Parasitol Today 3: 336-341.

Diotaiuti L, Paula OR, Falcão PL, Dias JCP 1995. Avaliação do programa do controle vetorial da doença de Chagas em Minas Gerais, Brasil, com referência especial ao Triatoma sordida. Bol Oficina Sanit Panan 118: 211-219.

Di Primo P 1957. Atual distribuição geográfica dos triatomídeos e seus índices de infecção no Rio Grande do Sul. An Fac Med Porto Alegre 17: 17-37.

Forattini OP, Rabello EX, Castanho MLS, Pattoli DGB 1970. Aspectos ecológicos da tripanossomíase americana. I. Observações sobre Panstrongylus megistus e suas relações com focos naturais da infecção em área urbana na cidade de São Paulo, Brasil. Rev Saúde Públ 4: 19-30.

IBGE-Instituto Brasileiro de Geografia e Estatística 1997. On line data: http: www.ibge.gov.br.

Lent H 1942. Estudos sobre os triatomíneos do estado do Rio Grande do Sul, com descrição de uma espécie nova. Rev Bras Biol 2: 219-231.

Lent H, Wygodzinsky P 1979. Revision of the Triatominae (Hemiptera, Reduviidae), and their significance as vectors as Chagas' disease. Bul Am Mus Nat Hist 163: 127-520.
Lucena DT 1959. Ecologia dos triatomíneos no Brasil. Rev Bras Malariol Doenç Trop 11: 577-635.

Savatella R, Calegari L, Puime A, Basmadjian, Rosa R, Guerrero J, Martinez M, Mendaro G, Briano D, Montero C, Wisnivesky-Colli C 1994. Perfil alimentario de Triatoma rubrovaria (Blanchard, 1843) (Hemiptera, Triatominae) en ámbitos peridomiciliarios, de una localidad rural de Uruguay. Rev Inst Med Trop São Paulo 36: 311-320.

Salvatella R, Rosa R, Basmadjian Y, Puime A, Calegari L, Guerrero J, Martinez M, Mendaro G, Briano D, Montero C, Wisnivesky-Colli C 1995. Ecology of Triatoma rubrovaria (Hemiptera, Triatominae) in wild and peridomestic environments of Uruguay. Mem Inst Oswaldo Cruz 90: 325-328.

Schofield CJ Dias JCP 1998. The Southern Cone initiative against Chagas disease. Adv Parasitol 42: 1-27.

Silva EOR, Dias JR J, Guarita OF 1969. Suspensão do rociado no combate ao Triatoma infestans em áreas do estado de São Paulo, Brasil. Rev Saúde Públ 3: 173-181.

Silva IG, Silva HHG 1993. Suscetibilidade de 11 espécies de Triatomíneos (Hemiptera, Reduviidae) à cepa ' $Y$ ' de Trypanosoma cruzi (Kinetoplastida, Trypanosomatidae). Rev Bras Entomol 37: 459-463.

Silveira AC, Rezende DF 1994. Epidemiologia e controle da transmissão vetorial da doença de Chagas no Brasil. Rev Soc Bras Med Trop 27 (Supl. III): 1122.

Silveira AC, Vinhaes MC 1999. Elimination of vectorborne transmission of Chagas disease. Mem Inst Oswaldo Cruz 94 (Suppl. I): 405-411.

Silveira AC, Feitosa VR, Borges R 1984. Distribuição de triatomíneos capturados em ambientes domiciliares no Brasil, durante o período de 1975/ 83. Rev Bras Malariol Doenç Trop 36: 15-312. 